\title{
XXXIII. EXPERIMENTAL PRODUCTION OF PLAGUE EPIDEMICS AMONG ANIMALS.
}

\author{
(Third communication.)
}

IN previous reports (vol. VI. p. 470 and vol. VII. p. 421), we described several series of experiments the results of which went to show that fleas and fleas alone were the transmitting agents of the infection of plague. It will be remembered that these experiments were carried out in a series of small godowns, the construction of which has been described in detail. The animals employed in the majority of previous experiments were guinea-pigs, though a limited number of experiments were carried out with monkeys. Gottschlich (Kolle and Wassermann's Handbuch der Pathogenen Mikroorganismen, Suppl. vol. II., 1907, p. 52) considers that the results obtained with guineapigs cannot be applied to rats as the latter animals, unlike guineapigs, feed on the carcases of their dead companions. Gottschlich while admitting that fleas may transmit the disease from rat to rat considers this method of spread to be of only subsidiary importance. He is of opinion that, among rats, plague is chiefly spread by the healthy animals feeding on the carcases of the plague infected. In order to examine the validity of these criticisms we decided to repeat the godown experiments using wild Bombay rats instead of guinea-pigs.

\section{Series I.}

The godowns used in this series were Nos. $1,2,5$ and 6 . It will be remembered that godowns Nos. 1 and 2 had roofs of country tiles which afforded protection to wild rats. Hence in these godowns there was a more or less abundant supply of rat fleas. The roofs of godowns Nos. 5 and 6 were of reinforced concrete which of course offered no shelter to wild rats. 
Early in February 1908 it was ascertained by guinea-pig tests that godowns Nos. 1 and 2 contained a large number of fleas, while Nos. 5 and 6 were free from fleas. 25 healthy rats were then introduced into each of the godowns. These rats were wild Bombay Mus rattus which had been kept in captivity for several weeks before being put into the godowns. It was necessary to remove the fleas from the rats intended for godowns Nos. 5 and 6 . This was done by immersing the rats momentarily in an emulsion of "Hydrocarbon" (a by-product in the manufacture of Pinsch's oil gas containing a considerable percentage of benzene). After immersion the rats were kept for some days in cages suspended above the ground until they had recovered from the effects of their immersion. Before being put in godowns Nos. 5 and 6 a certain number of them were examined for fleas. This method of removing fleas from the rats appeared to be effectual as we were never able to discover any fleas on the rats that had been dipped and subsequently kept in suspended cages. The mortality among the rats as a result of the immersion was however very high. A considerable number of rats died in the godowns, especially Nos. 5 and 6 , during the week following their introduction. These were replaced by fresh rats.

The following table shows the number of fleas caught on rats in each godown on several occasions before and during the progress of the experiments :

Flea counts in godowns.

\begin{tabular}{|c|c|c|c|c|c|c|c|c|}
\hline \multirow[b]{2}{*}{ Date } & \multicolumn{2}{|c|}{ Godown No. 1} & \multicolumn{2}{|c|}{ Godown No. 2} & \multicolumn{2}{|c|}{ Godown No. 5} & \multicolumn{2}{|c|}{ Godown No. 6} \\
\hline & $\begin{array}{l}\text { No. of rats } \\
\text { examined }\end{array}$ & $\begin{array}{l}\text { No. of } \\
\text { fleas }\end{array}$ & $\begin{array}{l}\text { No. of rats } \\
\text { examined }\end{array}$ & $\begin{array}{l}\begin{array}{l}\text { No. of } \\
\text { fleas }\end{array} \\
\text { tes }\end{array}$ & $\begin{array}{l}\text { No. of rats } \\
\text { examined }\end{array}$ & $\begin{array}{l}\text { No. of } \\
\text { fleas }\end{array}$ & $\overbrace{\begin{array}{l}\text { No. of rats } \\
\text { examined }\end{array}}$ & $\begin{array}{c}\text { No. of } \\
\text { fleas }\end{array}$ \\
\hline 23. I1. 08 & 6 & 120 & 6 & 76 & 8 & 0 & 8 & 0 \\
\hline 3. III. 08 & 3 & 49 & 2 & 13 & 3 & 3 & 2 & 1 \\
\hline 6. III. 08 & 一 & - & 一 & 一 & 3 & 1 & 3 & 0 \\
\hline 13. III. 08 & 2 & 22 & 2 & 31 & 3 & 0 & 3 & 2 \\
\hline 23. III. 08 & 3 & 56 & 3 & 49 & 3 & 3 & 3 & 5 \\
\hline 13. IV. 08 & 3 & 30 & 3 & 31 & 3 & 18 & $\mathbf{3}$ & 9 \\
\hline 24. IV. 08 & - & 一 & 一 & 一 & 3 & 49 & 3 & 48 \\
\hline
\end{tabular}

Note:-Fleas caught on rats in godowns Nos. 1 and 2 were subsequently returned to the godowns.

\section{Experiment I. Diagram I.}

It will be seen that quite early in the experiment fleas were present in small numbers in the control godown No. 5. The number of fleas increased considerably in April. Of 12 rats proved to have died of 
DIAGRAM

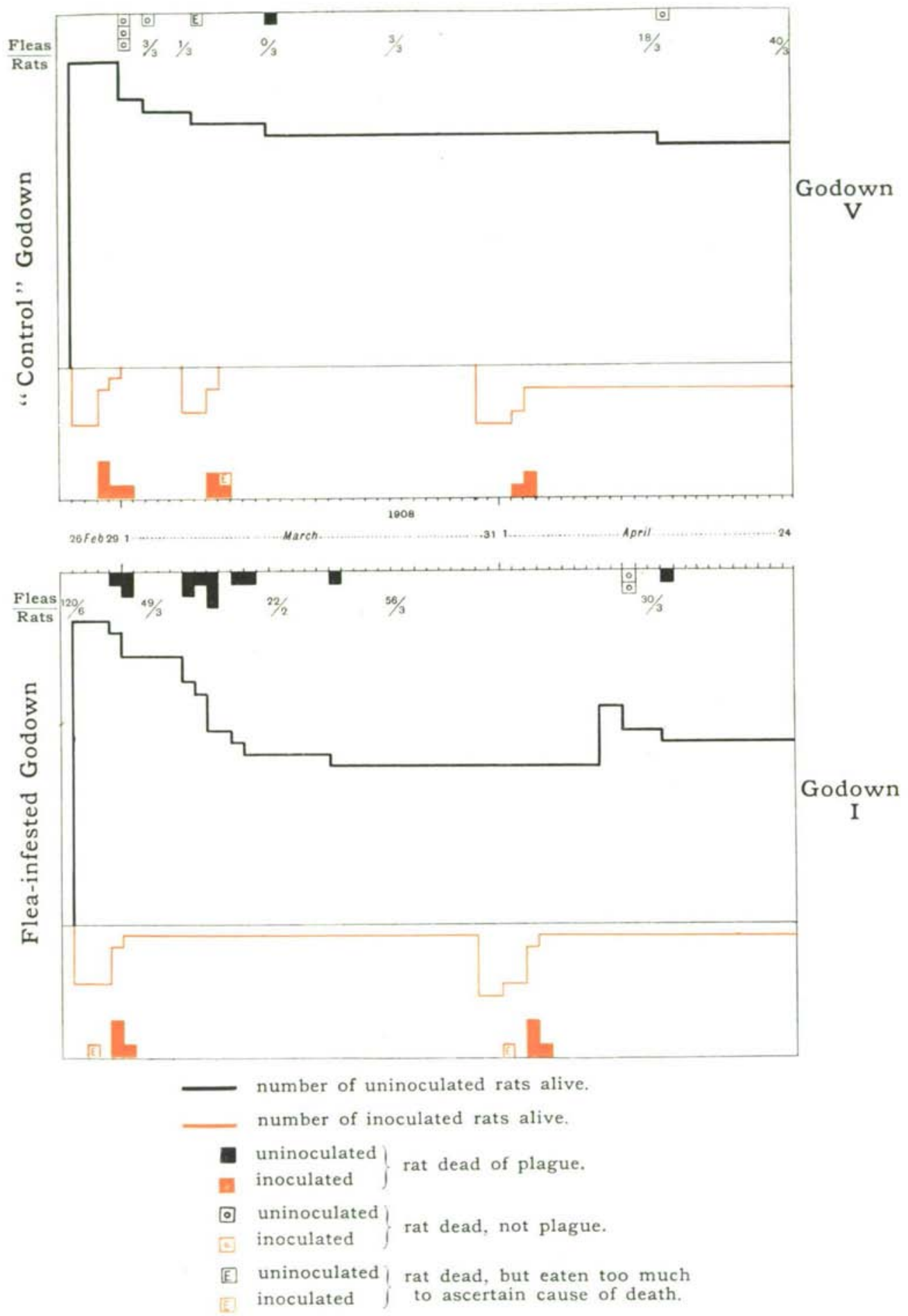




\section{DIAGRAM II}

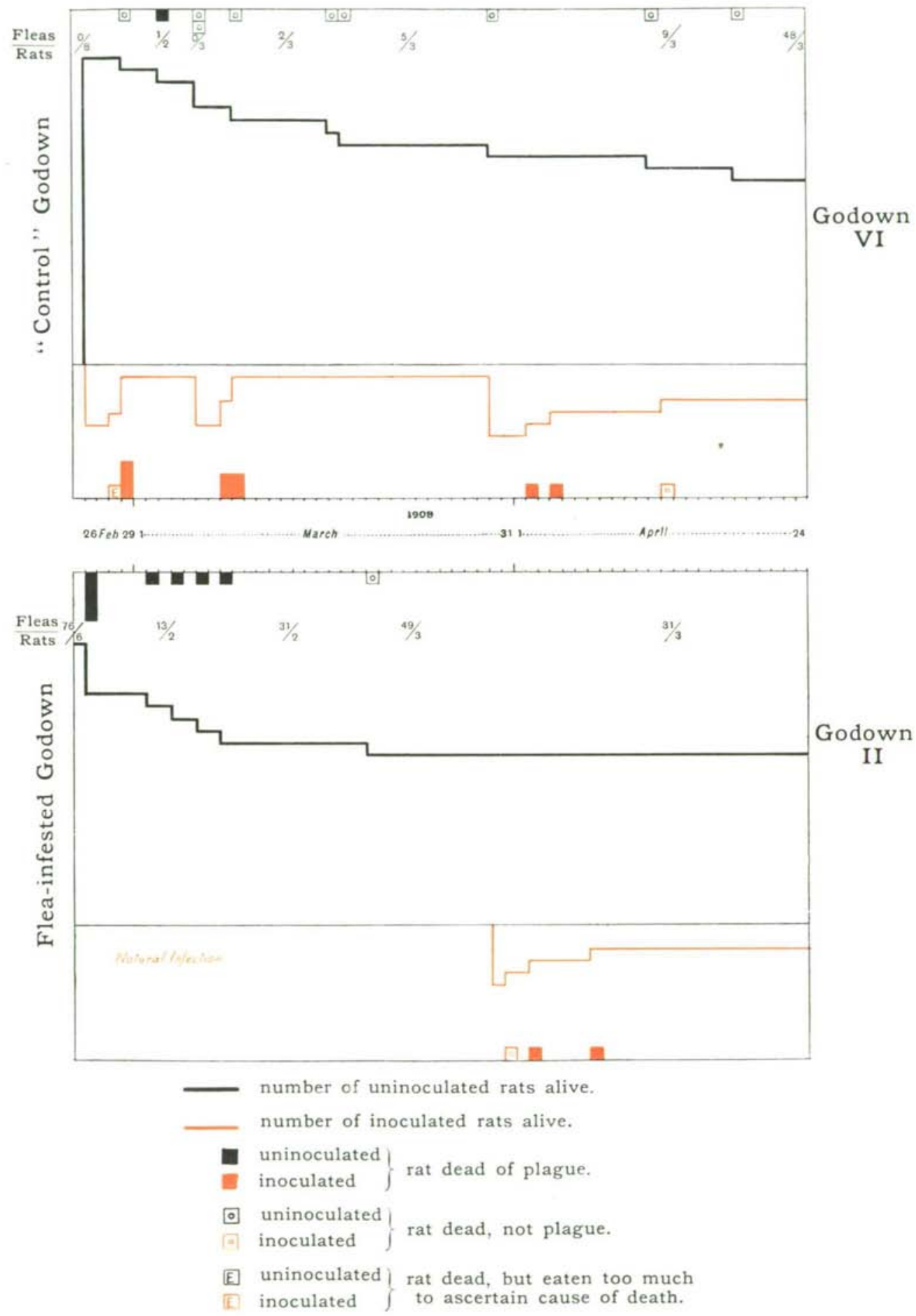


plague, the carcases of nine were more or less eaten. Only one uninoculated rat died of plague and it showed no signs of an intestinal infection.

In the flea-infested godown No. 1 uninoculated rats died of plague on the same day as the first inoculated rats died. This suggests that the godown was previously infected from wild rats living in the tiles of the roof (cf. godown 2, Experiment II). On April 9th five more uninoculated rats were put in the godown. Of these one died of plague on April 18th, showing that the godown was infective, though none of the survivors of the original epizootic became infected. This suggests that the survivors were immune.

The chief value of the experiment is that it shows that feeding may take place to a considerable extent without giving rise to an epizootic.

Experiment I. Feb. 26 th to April 24 th.

Godown 5

Godown 1

$$
\begin{aligned}
& \text { Inoculated rats } \\
& \text { Put in Died of plague }
\end{aligned}
$$

13

$\begin{array}{cc}9 & 3 \cdot 6 \\ 1 & 17\end{array}$

\section{Experiment II. Diagram II.}

In the control godown No. 6 fleas were present in small numbers and the number increased in April. In this godown only one out of 11 rats proved to have died of plague was eaten.

With reference to the heavy mortality from causes other than plague among the uninoculated rats in this godown, it may be remarked that two of them died from the effects of chloroform when being searched for fleas and several were suffering from ulcerations due to having been dipped in "Hydrocarbon" emulsion.

In godown 2 infection was started from wild rats living in the roof. As in the previous experiment we failed to infect any of the survivors of the epizootic by putting in a fresh lot of inoculated rats. None of the ten rats which died of plague in'this godown were eaten.

\section{Experiment II. Feb. 26th to April 24th.}

Godown 6 Godown 2

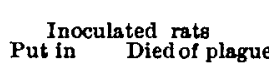

14

[5]

$\begin{array}{cccc}\begin{array}{c}\text { Uninoculated rats } \\ \text { Put in } \\ \text { Died of plague }\end{array} & \begin{array}{c}\text { Plague rats } \\ \text { eaten }\end{array} & \begin{array}{c}\text { Average } \\ \text { fleas per rat }\end{array} \\ 25 & 1 & 1 & 2 \cdot 5 \\ 23 & \mathbf{8} & 0 & 12 \cdot 5\end{array}$




\section{Series II.}

In these experiments a series of new godowns were used, numbered 7 to 12. They were built throughout of reinforced concrete; there was therefore no natural supply of fleas from rats living in the roofs. The flea-infected godowns were deliberately stocked with fleas, about 400 fleas being put each week into each of the godowns 10, 11 and 12. For about six weeks the numbers found remained small, but later on they became abundant, presumably because breeding had started. In other respects the experiments of this series were done in the same way as those in Series I.

\section{Experiment III. Diagram III.}

No deaths from plague occurred among the uninoculated rats in godown No. 7 as long as it remained free from fleas, although 15 of the inoculated rats died from plague. Five weeks after the commencement of the experiment a flea count showed that fleas were now present in the godown in small numbers and a few days later the uninoculated rats began to die. Of the 21 rats that died of plague in this godown none were eaten. On Feb. 8 the surviving rats were inoculated with a dose of an emulsion of a plague rat's spleen $(=1 / 1000$ grain of spleen): 4 of the $12(33 \%)$ died of plague, while of 20 control rats inoculated at the same time $95 \%$ died of plague.

In the flea-infested godown No. 10, nine of the uninoculated rats died of plague. The carcases of four inoculated rats and seven uninoculated were found to have been eaten, several almost completely. Of the nine uninoculated rats which were proved to have died of plague, two had definite mesenteric buboes, three had no buboes and the remaining four had been eaten to such an extent that the presence or absence of a bubo could not be determined. It is evident then that at least two of these rats were infected by feeding.

An attempt to re-start the epizootic by putting in infected rats and six infected guinea-pigs failed.

On Feb. 3rd the surviving rats where removed to godown No. 12 which was at the time highly infective for guinea-pigs and were kept there for two weeks. None of them contracted plague. 


\section{DIAGRAM III}

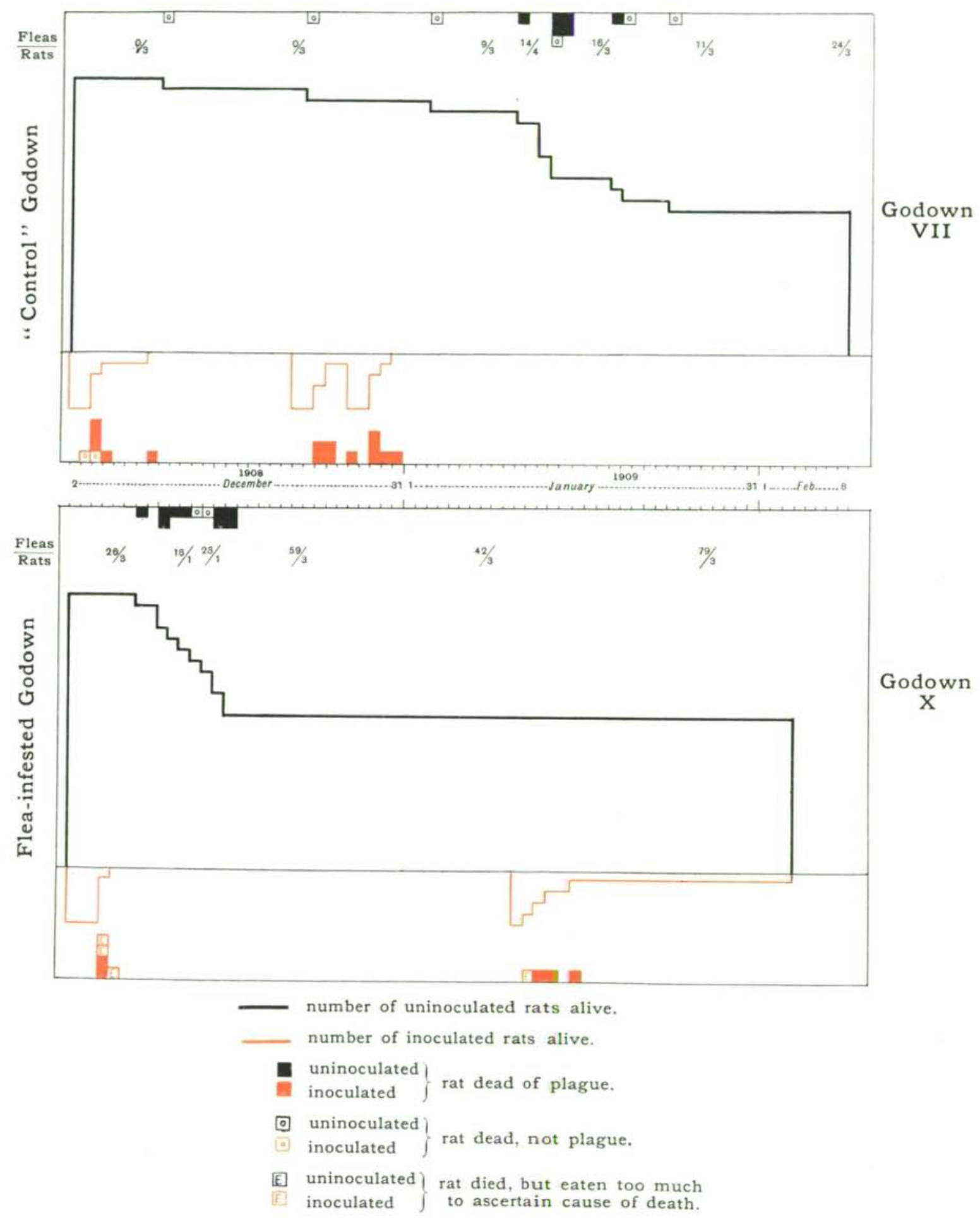




\section{DIAGRAM IV}
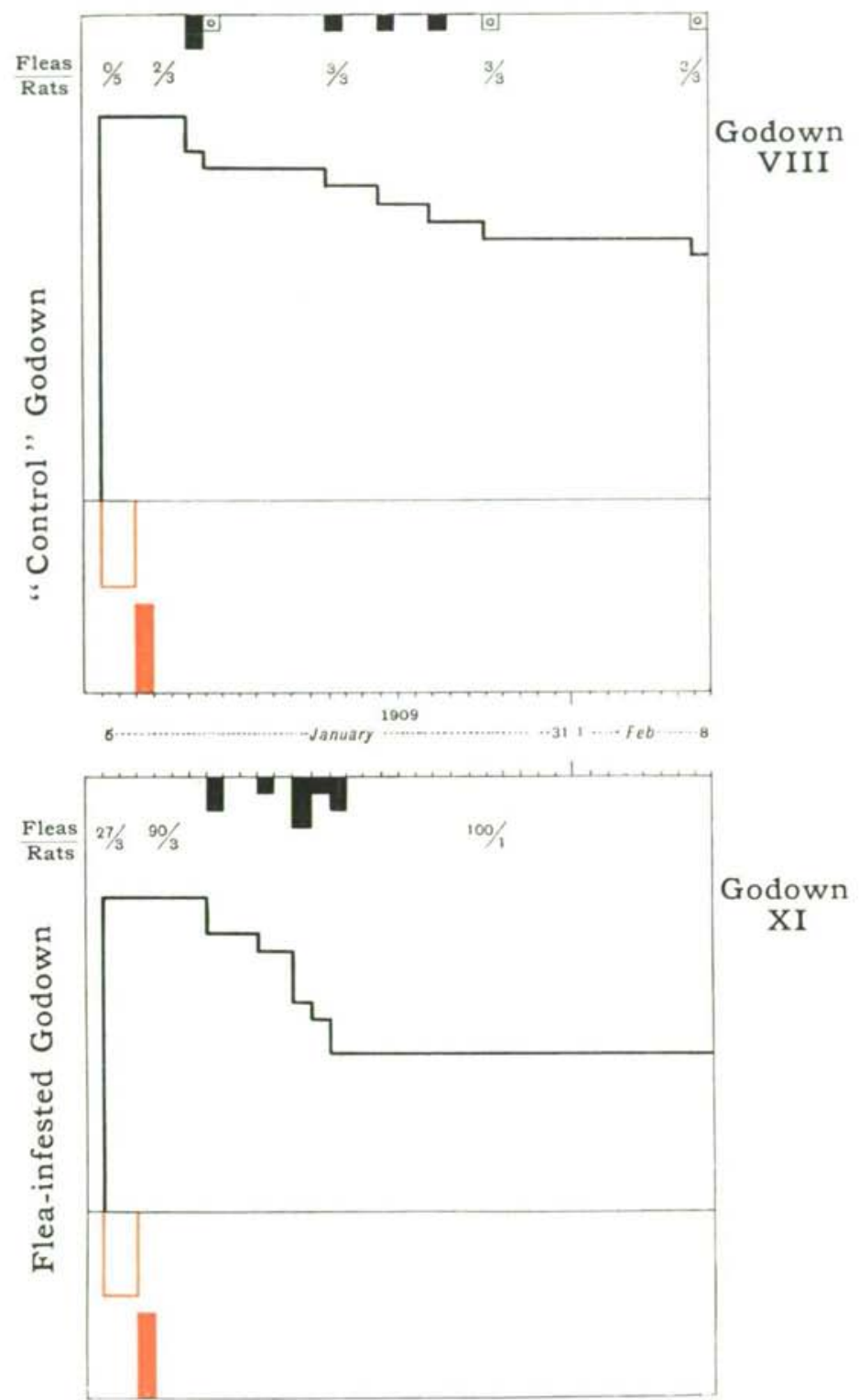

- number of uninoculated rats alive.

number of inoculated rats alive.

- uninoculated)

Inoculated rat dead of plague.

믄 inoculated $\}$ rat dead, not plague.

[E] uninoculated) rat dead, but eaten too much

[E] inoculated $j$ to ascertain cause of death. 


\section{DIAGRAM V}
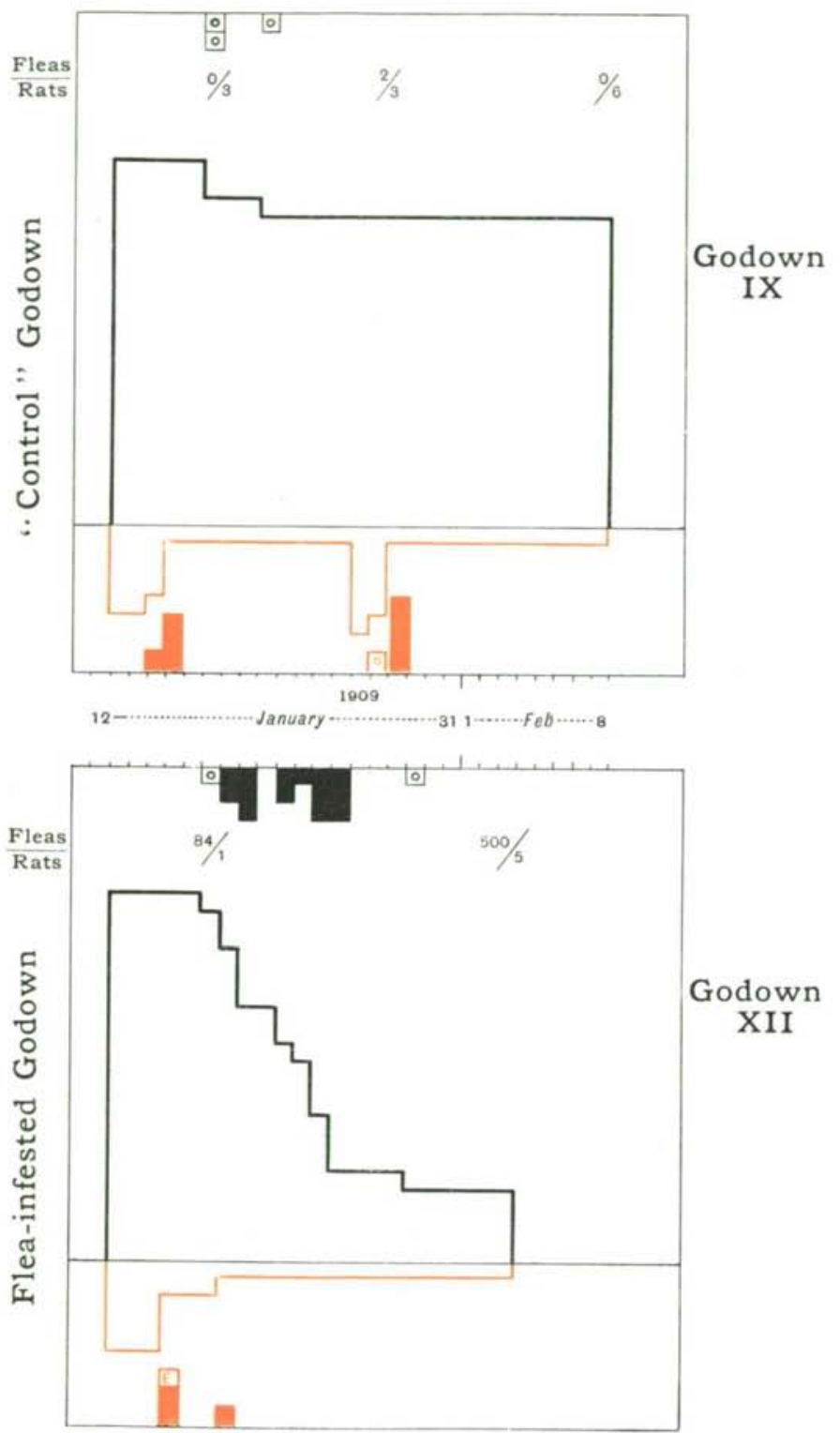

number of uninoculated rats alive.

number of inoculated rats alive.

- uninoculated

inoculated rat dead of plague.

D uninoculated) rat dead, not plague.

B inoculated $\}$ rat dead, not plague.

[E uninoculated) rat dead, but eaten too much

[E inoculated $\int$ to ascertain cause of death. 
On Feb. 18th the 14 surviving uninoculated rats were inoculated subcutaneously with a dose of an emulsion of the spleen of a plague rat $(=1 / 5000$ grain of spleen). None of these rats died of plague, whereas of 30 control rats which were inoculated at the same time, $60 \%$ died of plague.

Experiment III. Dec. 2nd to Feb. 8th.

Godown 7

Godown 10

\begin{tabular}{cc}
\multicolumn{2}{c}{ Inoculated rats } \\
Put in & Died of plague \\
17 & 15 \\
10 & 5
\end{tabular}

\section{Experiment IV. Diagram IV.}

Fleas were present in the control godown, No. 8, in small numbers throughout the experiment. The epizootic consisted of five cases spread over a fortnight. None of the rats that died in this godown were eaten. On Feb. 8, ten of the surviving rats were inoculated with the equivalent of $1 / 1000$ grain of the spleen of a plague-infected rat. Of these eight $(80 \%)$ died of plague, while of 20 control rats $95 \%$ died of plague.

In the flea-infested godown No. 11, two of the 14, rats that died of plague were partially eaten. The immunity of the surviving rats was tested by subcutaneous inoculation on Feb. 18th. Of nine rats which received the equivalent of $1 / 5000$ grain of the spleen of a plague rat, none died, whereas of 30 control rats $60 \%$ died.

This experiment illustrates the more rapid course of the epizontic in the godown with a higher flea infestation.

Godown 8

Godown 11

Experiment IV. Jan. 5th to Feb. 8th.

\begin{tabular}{cccccc}
$\begin{array}{c}\text { Inoculated rats } \\
\text { Put in }\end{array}$ & \multicolumn{2}{c}{$\begin{array}{c}\text { Uninoculated rats } \\
\text { Died of plague }\end{array}$} & $\begin{array}{c}\text { Put in } \\
\text { Died of plague }\end{array}$ & $\begin{array}{c}\text { Plague rats } \\
\text { eaten }\end{array}$ & $\begin{array}{c}\text { Average } \\
\text { fleas per rat }\end{array}$ \\
5 & 5 & 22 & 5 & 0 & $0 \cdot 7$ \\
5 & 5 & 18 & 9 & 2 & 31
\end{tabular}

\section{Experiment $V$. Diagram $V$.}

In this experiment special precautions were taken to render the control godown, No. 9, as far as possible flea-free. Immediately before commencing the experiment the rats already in the godown were removed and again freed from fleas under chloroform before being put 
back. While the rats were out the godown was cleaned and washed out with pure kerosine oil. The control godown remained practically free from fleas throughout the experiment. None of the rats which died were eaten. On Feb. 8th the surviving rats were inoculated subcutaneously with the equivalent of 1/1000 grain of spleen of a plague rat. Of 16 thus inoculated $15(=94 \%)$ died of plague, while of 20 controls $95 \%$ died of plague.

In the flea-infested godown, No. 12, the number of fleas was far in excess of that observed in other experiments. Of 17 rats dead of plague three were eaten,- - one almost completely. None of the 14 uninoculated rats that died of plague showed signs of an intestinal infection. On Feb. 3rd four uninoculated rats which remained alive were inoculated with the equivalent of $1 / 1000$ grain of the spleen of a plague rat. None of these died of plague, while of two control rats one died of plague.

This experiment illustrates well the rapid and extensive spread of plague among the rats in the presence of very large numbers of fleas.

Godown 9

Godown 12

Experiment $V$. Jan. 12th to Feb. 8th.

$\begin{array}{cccccc}\begin{array}{c}\text { Inoculated rats } \\ \text { Put in }\end{array} & \begin{array}{c}\text { Uninod of plague } \\ \text { Put in }\end{array} & \begin{array}{c}\text { Died of plague } \\ \text { Pieden }\end{array} & \begin{array}{c}\text { Plague rats } \\ \text { eaterage } \\ \text { fleas per rat }\end{array} \\ 10 & 8 & 20 & 0 & 0 & 0 * 2 \\ 5 & \mathbf{3} & 20 & \mathbf{1 4} & 3 & 97\end{array}$

\section{Experiment VI. Diagram VI.}

The control godown, No. 8, remained free from fleas throughout. None of the rats that died in this godown were eaten. On April 15th sixteen rats remaining in the godown were inoculated subcutaneously with the equivalent of $1 / 2000$ grain of a spleen of a plague-infected rat. Of this number seven $(47 \%)$ died of plague, as compared with $40 \%$ of 23 controls.

None of the rats that died in the flea-infested godown No. 11 were eaten. Of nine survivors inoculated with the same dose of spleen as the rats in the control godown none died of plague.

\section{Experiment VI. March 4th to April 15 th.}

Godown 8 Godown 11

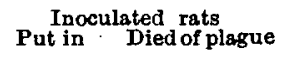

15

5

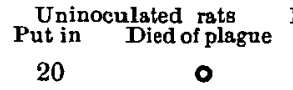

20

o
Plague rats
eaten $\quad \begin{gathered}\text { Average } \\ \text { feas per rat }\end{gathered}$

0 nil

o 10.5 


\section{DIAGRAM VI}

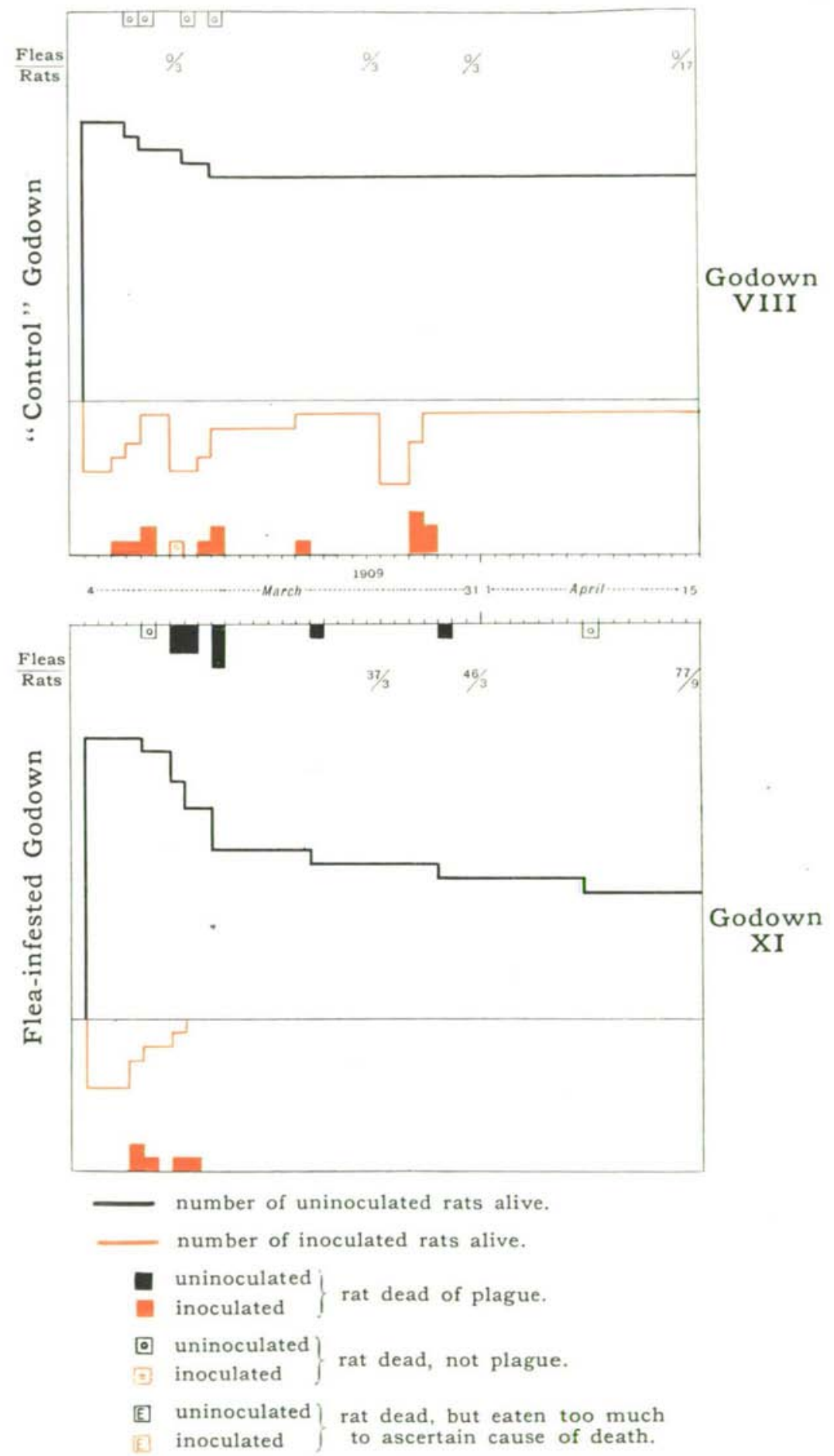




\section{DIAGRAM VII}
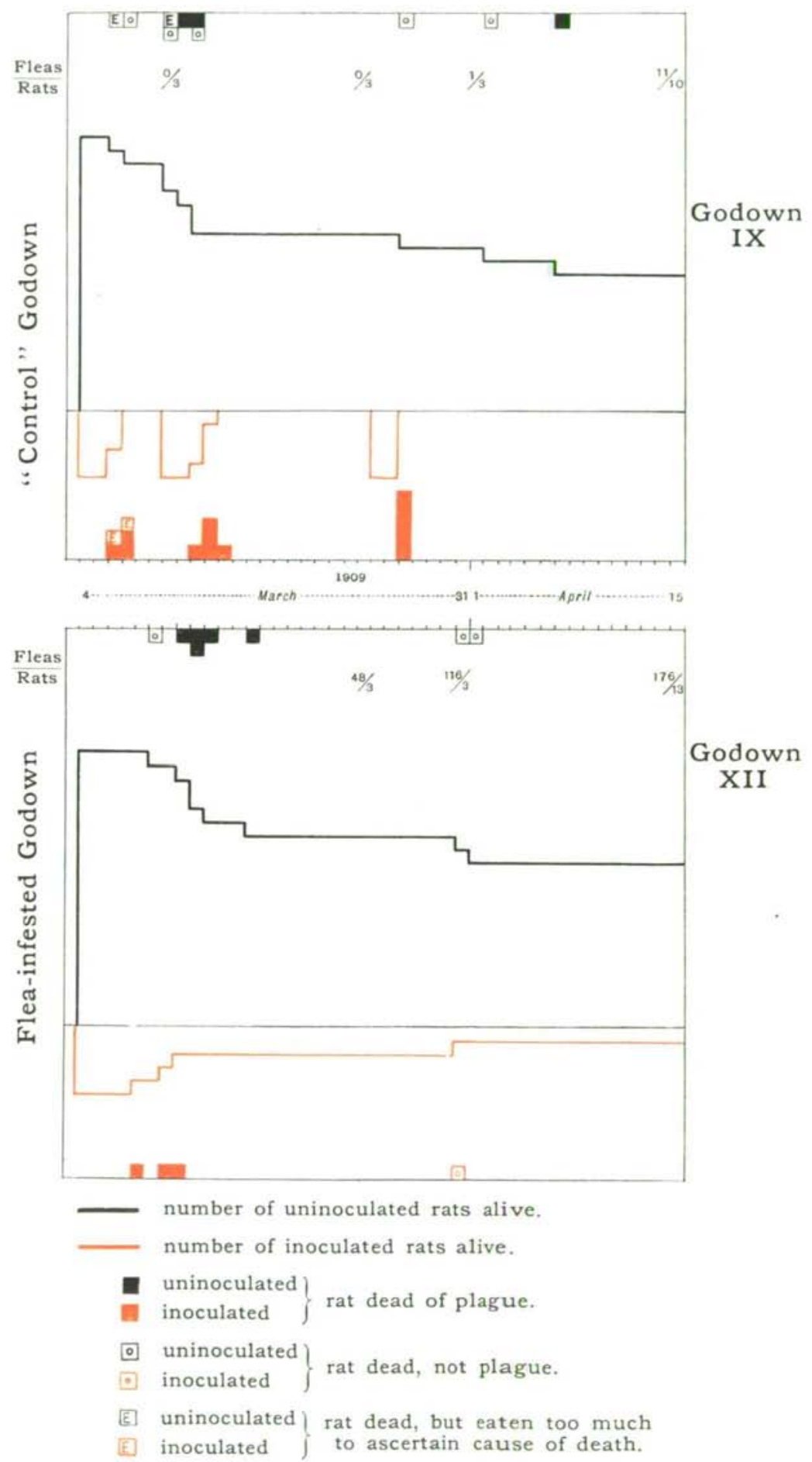


\section{Experiment VII. Diagram VII.}

In control godown, No. 9, many of the carcases were eaten. Of the first five inoculated rats put in and that died, two were almost completely and one partially eaten, while two of the second five were partially eaten. Of the uninoculated rats that died, two were eaten to such an extent that the cause of death could not be determined, and two of the three rats that were proved to be plague-infected were partially eaten.

On April 15th nine rats from this godown were inoculated with $1 / 2000$ of a grain each of the spleen of a plague-infected rat : three of them died of plague, as compared with $40 \%$ of the controls.

\section{Experiment VII. Warch 4th to April $15 t h$.}

Godown 9

Godown 12

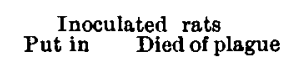

15

5

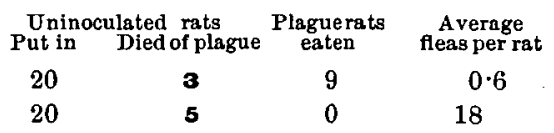

$0 \cdot 6$

\section{SERIES III.}

In this series the new godowns, 7 to 12 , were used. The technique differed from that previously used in three particulars. In the first place the godowns were further protected from fleas by building a gutter filled with water about 6 inches wide in front of the doorways. In the second place the godowns were more effectively cleared of fleas before the experiments commenced by fumigating them with hydrocyanic acid vapour after the washing with kerosine emulsion which had alone been previously employed; eggs and larvae are killed by this method as well as adult fleas. The third point of difference to be noted is that the inoculated rats which were introduced were confined in cages, instead of running loose, on the floor of the godowns: this did not altogether prevent their carcases being partially eaten. The absence of fleas in the control godowns was controlled by guinea-pig flea traps. The rats were cleared of fleas by dipping in "Hydrocarbon" as before; they were then hung up for a week or two where they were inaccessible to fleas and finally examined under chloroform to make sure that they wore free from fleas before being put into the flea-free godowns. In this way we succeeded in keeping a number of godowns almost if not quite free from fleas for considerable periods. 
Experiment VIII.

\section{A. Control Godowns.}

Godown No. 7. This godown failed as control as it became flea infested almost from the start. A death from plague among the uninoculated rats occurred in the first week and a flea found on the rat which died of plague showed abundant $B$. pestis in the stomach.

Godown No. 8. Fifteen uninoculated rats and five rats inoculated with a virulent emulsion of a plague guinea-pig spleen were put in on Sept. 24. These rats were all flea-free. Four of the inoculated rats died of plague by Sept. 29. One died from some other cause. A second lot of five inoculated rats were put in on Oct. 13. All died of plague on Oct. 15. The experiment was continued until Nov. 2, and during the whole period no death from plague occurred among the fifteen uninoculated rats. A weekly flea-count showed the godown to be flea-free throughout. None of the rats which died in this godown were eaten.

Godown No. 9. Fifteen uninoculated rats and five inoculated rats were put into this godown on Sept. 24. Three of the inoculated rats died of plague by Sept. 30: one died of some other cause and one survived. A second lot of five inoculated rats was introduced on Oct. 13. All of these died of plague by Oct. 16. The godown remained flea-free throughout until Nov. 2 when one flea was found and the experiment terminated. No death from plague among the uninoculated rats occurred in this godown. No rats which had died of plague in this godown were eaten.

\section{B. Flea Godowns.}

Godown No. 10. Fifteen uninoculated rats and five rats inoculated with the same emulsion as was used to infect the rats in the control godowns were introduced on Sept. 24. All five inoculated rats were dead from plague by Sept. 29. Five more inoculated rats were put in on Oct. 13: these were all dead of plague by Oct. 22. One uninoculated rat died of plague on Oct. 6 and another on Oct. 14. The average of the weekly number of fleas present during this experiment was 2.5 per rat. None of the rats dead of plague in this godown were eaten.

Godown No. 11. Five inoculated and fifteen uninoculated rats put in on Sept. 24. Four inoculated rats were dead of plague by Sept. 28 : 
one survived. Five more inoculated rats were put in on Oct. 13. Four of these were dead of plague by Oct. 17, one survived.

One uninoculated rat died of plague on Sept. 27, a second on Oct. 26, and a third on Nov. 2. The average number of fleas for the period was 1.4 per rat. No plague rats eaten.

Godown No. 12. Five inoculated and fifteen uninoculated rats were introduced on Sept. 24. Three inoculated rats died of plague by Sept. 30 : one died less acutely of plague on Oct. 9 : one survived.

Five more inoculated rats were put in on Oct. 13: four of these died of plague by Oct. 17, and one from some other cause. No death from plague occurred among the uninoculated rats. Average of fleas per rat for the period was seven per rat. One plague rat eaten.

Experiment VIII. Sept. 24th to Nov. 2nd.

\begin{tabular}{|c|c|c|c|c|c|c|}
\hline \multirow{2}{*}{$\begin{array}{c}\text { Godown } \\
\text { No. } 7\end{array}$} & \multicolumn{2}{|c|}{$\begin{array}{l}\text { Inoculated rats } \\
\text { Put in Dead of plague }\end{array}$} & \multicolumn{2}{|c|}{$\begin{array}{l}\text { Uninoculated rats } \\
\text { Put in Dead of plague }\end{array}$} & \multirow{2}{*}{$\begin{array}{c}\text { Plague rats } \\
\text { eaten } \\
0\end{array}$} & Flea count \\
\hline & 10 & 9 & 15 & 1 & & $\begin{array}{l}1 \text { found on Bept. } 27 \\
\text { contained B.pestis } \\
\text { in its stomach. }\end{array}$ \\
\hline No. 8 & 10 & 9 & 15 & $\mathbf{0}$ & 0 & Nil. \\
\hline No. 9 & 10 & 8 & 15 & 0 & 0 & Nil. \\
\hline No. 10 & 10 & 10 & 15 & 2 & 0 & Average 2.5 per rat. \\
\hline No. 11 & 10 & 8 & 15 & $\mathbf{3}$ & 0 & Average 1.4 per rat. \\
\hline No. 12 & 10 & 8 & 15 & 0 & 1 & Average 7 per rat. \\
\hline
\end{tabular}

Experiment $I X$.

\section{A. Control Godowns.}

Of these godowns only No. 9 remained perfectly flea-free, one flea being found in No. 7 and one in No. 8 during the course of the experiment.

Godown No. 7. Five inoculated and fifteen uninoculated rats were put in on Nov. 5. Four inoculated rats were dead of plague by Nov. 10: one survived. Four more inoculated rats were put in on Nov. 17, three of which died of plague by Nov. 19 and the fourth died of some other cause. A third lot of five inoculated rats was introduced on Nov. 26, three of which died of plague by Nov. 29: two survived. No deaths from plague occurred among the uninoculated rats. One flea was found in the godown on Nov. 15 and removed. No more fleas were found until Dec. 13, when one was found and the experiment stopped. No plague rats were eaten. 
Godown No. 8. Five inoculated and fifteen uninoculated rats were put in on Nov. 5. Three of the inoculated rats were dead of plague by Nov. 10: two survived. Fire more inoculated rats were put in on Nov. 17, all of which were dead of plague by Nov. 20. A third lot of five was introduced on Nov. 26, all of which died of plague by Dec. 3 . The total number of inoculated rats dead of plague in the godown is thus thirteen. Of the fifteen uninoculated rats exposed to infection none died of plague. One flea was found in the godown on Nov. 29 and removed. When the experiment was terminated on Dec. 13 the godown was flea-free. One plague rat was partly eaten during this experiment.

Godown No. 9. Five inoculated and fifteen uninoculated rats were put in on Nov. 5. Three of the inoculated rats were dead of plague by Nov. 9 and a fourth died of plague on Nov. 16: one survived. Four more inoculated rats were introduced on Nov. 17, all of these died of plague by Nov. 21. A third lot of five inoculated rats was put in on Nov. 26 ; four of these died of plague by Dec. 1, one survived. The total number of inoculated rats which died of plague in this godown was 12 . None of the fifteen uninoculated rats developed plague. This godown remained flea-free until the termination of the experiment. No plague rats eaten.

\section{B. Flea Godowns.}

Godown No. 10. Five inoculated and fifteen uninoculated rats were put in on Nov. 5. All the inoculated rats died of plague by Nov. 9. A second lot of five inoculated rats was put in on Nov. 25: all of these died of plague by Nov. 30. One uninoculated rat died of plague on Nov. 14, a second one on Nov. 18, a third on Nov. 20, a fourth on Nov. 22, and a fifth on Nov. 29. The average number of fleas present for the period was 13 per rat. No plague rats eaten.

Godown No. 11. Five inoculated and 15 uninoculated rats were put in on Nov. 5. Four of the inoculated rats died of plague by Nov. 8: one survived. Five more inoculated rats were put in on Nov. 26: all of these died of plague by Dec. 1. Deaths from plague among the uninoculated rats occurred on the 13th, 14th, 18th, 20th, and 22nd November-five in all. The average flea count during the epizootic was 18 per rat. Four.rats which died from plague in this godown were partially eaten.

Godown No. 12. Five inoculated and fifteen uninoculated rats were introduced on Nov. 5. All five inoculated rats were dead of 


\section{Reports on Plague Investigations in India}

plague by Nov. 8. Five more inoculated rats were put in on Nov. 26 : all died of plague by Nov. 30. Three uninoculated rats died of plague on Nov. 14, two on Nov. 15, one on Nov. 18 and one on Nov. 20. Average number of fleas present during the period was 39 per rat. No plague rats were eaten in this godown.

Experiment IX. Nov. 5th to Dec. 13 th.

\begin{tabular}{|c|c|c|c|c|c|c|}
\hline \multirow{3}{*}{$\begin{array}{c}\text { Godown } \\
\text { No. } 7\end{array}$} & \multirow{2}{*}{\multicolumn{2}{|c|}{$\begin{array}{l}\text { Inoculated rats } \\
\text { Put in Dead of plague }\end{array}$}} & \multirow{2}{*}{\multicolumn{2}{|c|}{$\begin{array}{l}\text { Uninoculated rats } \\
\text { Put in Dead of plague }\end{array}$}} & \multirow{2}{*}{$\begin{array}{l}\text { Plague rats } \\
\text { eaten }\end{array}$} & \multirow{2}{*}{ Flea count } \\
\hline & & & & & & \\
\hline & 14 & 10 & 15 & o & 0 & $\begin{array}{l}\text { One thea found on } \\
\text { Nov. } 15 \text {. }\end{array}$ \\
\hline No. 8 & 15 & 13 & 15 & o & 1 & $\begin{array}{l}\text { One tlea found on } \\
\text { Nov. } 29 \text {. }\end{array}$ \\
\hline No. 9 & 14 & 12 & 15 & o & 0 & Nil. \\
\hline No. 10 & 10 & 10 & 15 & 5 & 0 & Average 13 per rat. \\
\hline No. 11 & 10 & 9 & 15 & 5 & 4 & Average 18 per rat. \\
\hline No. 12 & 10 & 10 & 15 & 7 & 0 & Average 39 per rat. \\
\hline
\end{tabular}

\section{Experiment $X$.}

\section{A. Control Godowns.}

Godown $N_{0}$. 7. Five inoculated and fifteen uninoculated flea-free rats were put in on Dec. 21. All the inoculated rats were dead of plague by Dec. 24. The godown remained tlea-free until Jan. 17 when it was found flea infested. No deaths from plague occurred among the uninoculated rats, the last plague death in the godown having occurred three weeks before it became flea infested. No plague rats were eaten in this godown.

Godown No. 8. Five inoculated and fifteen uninoculated rats were put in on Dec. 21. All the inoculated rats were dead of plague by Dec. 24. None of the uninoculated rats died of plague. The godown remained flea-free until the termination of the experiment on Jan. 24. One plague rat in this godown was partially eaten.

Godown No. 9. Five inoculated and fifteen uninoculated flea-free rats were introduced on Dec. 24. Four inoculated rats were dead of plague and one from some other cause by Dec. 26. The godown remained flea-free throughout and there were no deaths from plague among the uninoculated rats. Two plague rats in the godown were partially eaten. 


\section{B. Flea Godowns.}

Godown No. 16. Five inoculated and fifteen uninoculated rats were put in on Dec. 21. All the inoculated rats died of plague by Dec. 2:3. The first plague death among the uninoculated rats occurred on Dec. 28. Between that date and Jan. 3, seven more died of plague. Another death occurred on Jan. 10 and the last one on Jan. 17. Ten out of the fifteen uninoculated rats exposed to infection in this godown thus died of plague. The flea count during the progress of this epizootic was 34 per rat. One rat which died of plague in this godown was partially eaten.

Godown No. 11. Five inoculated and fifteen uninoculated rats were put in on Dec. 21. All five inoculated rats were dead of plague by Dec. 24. The first plague death among the uninoculated rats occurred on Dec. 30 . Four more deaths occurred on the four succeeding days and a last one on Jan. 6; the total number of uninoculated rats dying of plague was six. The flea count for the period was 29 per rat.

Godown No. 12. Five inoculated and fifteen uninoculated rats were introduced on Dec. 21. All five inoculated rats were dead of plague by Dec. 24. Three uninoculated rats died of plague on Dec. 25, four more on Dec. 26, three on Dec. 27 and one on Jan. 1st, the total number of rats succumbing to the epizootic being 11 out of the 15 . The flea count during the experiment averaged 48 per rat. No plague rats were eaten in this godown.

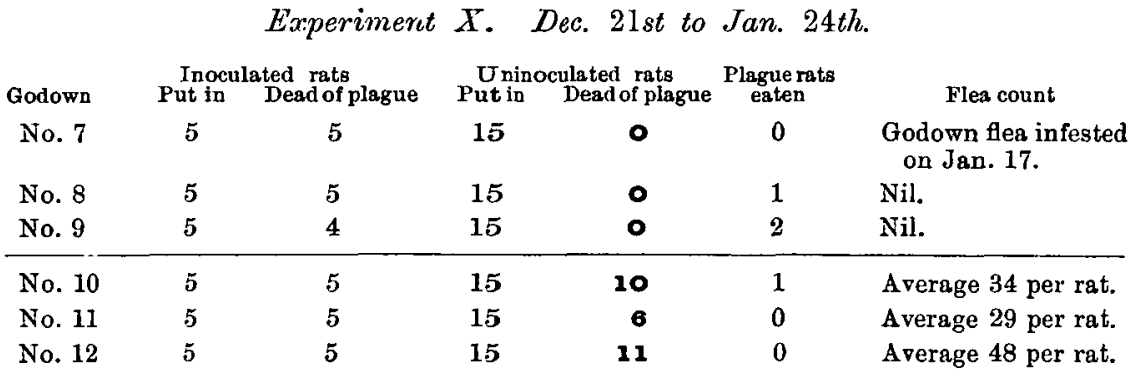

\section{Experiment $X Y$.}

\section{A. Control Godowns.}

Godown $N_{0}$. 7. Fifteen uninoculated rats and five rats inoculated with a virulent emulsion of plague rat's spleen were put into this godown on Feb. 3. Four of the inoculated rats died of plague by 
Feb. 7. Five more inoculated rats were introduced on Feb. 25, four of which died of plague by Feb. 28. The experiment was continued till March 3, and the godown remained flea-free throughout. No deaths from plague occurred among the uninoculated rats. None of the rats dead of plague were eaten.

Godown No. 8. Fifteen uninoculated and five inoculated rats were put in on Feb. 3. All the inoculated rats died of plague by Feb. 8. Five more inoculated rats were put in on Feb. 25, four of which died of plague by Feb. 28. The godown remained flea-free until March 7, when one flea was found. The experiment was terminated three days later. No deaths from plague occurred among the uninoculated rats. No plague rats were eaten.

Godown No. 9. Fifteen uninoculated and five inoculated rats were put in on Feb. 3. Three of the inoculated rats died of plague by Feb. 6 ; two survived. A second lot of five inoculated rats was put in on Feb. 25, all of which died on Feb. 27. The godown remained flea-free until March 7 when two fleas were found. The experiment was terminated three days later. No deaths from plague occurred among the uninoculated rats in this godown. No plague rats were eaten.

\section{B. Flea Godowns.}

Godown No. 10. Fifteen uninoculated rats and five rats inoculated with the same emulsion as was used in the Hea-free godowns were introduced on Feb. 3. Only two of the inoculated rats died of plague (on Feb. 5 and 6), the other three surviving. The first uninoculated rat which developed plague died on Feb. 9. Another died on Feb. 10, and seven more between Feb. 12 and 16 : nine deaths in all. Five more inoculated rats were introduced on Feb. 25, all of which died of plague by Feb. 28. No more uninoculated rats developed plague after the introduction of this second lot of inoculated rats. No plague rats were eaten. The average flea count for the period was 20 per rat. After the experiment ended on March 10, three rats were put in to provide food for the fleas; none died of plague.

Godown No. 11. Fifteen uninoculated and five inoculated rats were put in on Feb. 3. Four of the inoculated rats died of plague by Feb. 12: the tifth rat lived until Feb. 23 and died of subacute plague. One uninoculated rat died of plague on Feb. 6, the day after the first two inoculated rats died. Other deaths of uninoculated rats occurred on Feb. 9, 13, 14 and 20. Five more inoculated rats were introduced on 
Feb. 25: two of these died of plague on Feb. 27, and one on Feb. 26. One more uninoculated rat died on Feb. 27. The total number of uninoculated rats dying of plague is thus six, five of which deaths occurred before the introduction of the second lot of inoculated rats. The flea count for the period averaged 14 per rat. One plague rat was partly eaten. After the experiment ended on March 10, three fresh rats were put in ; one died of plague during the following week.

Godown No. 12. Fifteen uninoculated and five inoculated rats were put into this godown on Feb. 3. Four inoculated rats died of plague by Feb. 7. One uninoculated rat died of plague on Feb. 8, two on Feb. 11, and a fourth on Feb. 12. A second lot of five inoculated rats was put in on Feb. 25, all of which died of plague by March 1 . No more uninoculated rats died of plague. The flea count during the progress of the experiment averaged 15 fleas per rat. No plague rats were eaten. After the experiment ended on March 10, three fresh rats were put in : two died of plague during the following week.

Experiment XI. Feb. 3rd to March 10th.

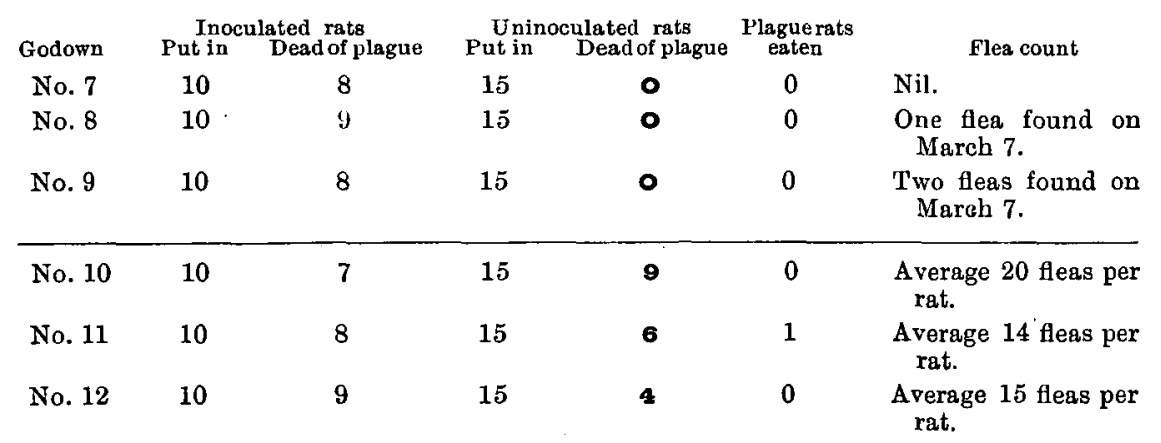

Experiment XII.

A. Control Godowns.

Godown No. 7. Fifteen uninoculated rats and five rats inoculated with an emulsion of a plague rat spleen were put in on March 22. The five inoculated rats died of plague on March 24. Five more were introduced on April 7, all of which died of plague by April 16, and a third lot of five put in on April 19 all died of plague on April 21. The godown remained flea-free until April 25 when one flea was found. The 
experiment was terminated a week later, no deaths from plague having occurred among the uninoculated rats. No plague rats were eaten.

Godown No. 8. Fifteen uninoculated flea-free rats and five inoculated rats were put in on March 22. All five inoculated rats were dead of plague by March 25. Five more inoculated rats were put in on April 7, four of which died of plague by April 11. A third lot of five was introduced on April 19 all of which died of plague on April 21. The godown remained flea-free throughout and none of the uninoculated rats died of plague. The experiment was terminated on May 2nd. No plague rats were eaten.

Godown No. 9. Fifteen uninoculated and five inoculated rats were put in on March 22. The five inoculated rats died of plague by March 29. Five more inoculated rats were put in on April 7, four of which died by April 19. A third lot of five was introduced on April 19, all of which died of plague on April 21. The godown remained flea-free until April 25, when four fleas were found. No plague rats were eaten.

\section{B. Flea Godowns.}

Godown No. 10. Fifteen uninoculated rats and five rats inoculated with the same emulsion as those in the control godowns were put in on March 22. Three of the inoculated rats died of plague on March 24 and two on March 25. The epizootic in this godown commenced on March 30 and progressed rapidly, the whole fifteen uninoculated rats being wiped out in a week, as follows :-

\begin{tabular}{crrrr} 
March & 30 & $\ldots$ & $\ldots$ & 2 \\
$\Rightarrow$ & 31 & $\ldots$ & $\ldots$ & 2 \\
April & 1 & $\ldots$ & $\ldots$ & 2 \\
$"$ & 2 & $\ldots$ & $\ldots$ & 3 \\
$"$ & 3 & $\ldots$ & $\ldots$ & 2 \\
$"$ & 4 & $\ldots$ & $\ldots$ & 2 \\
$"$ & 5 & $\ldots$ & $\ldots$ & 2 \\
\hline
\end{tabular}

The flea count during this epizootic was 11 per rat. No plague rats were eaten. At the end of the experiment, six fresh rats were put in: four of these died of plague.

Godown No. 11. Fifteen uninoculated and five inoculated rats were put in on March 22. All the inoculated rats died of plague by

Journ. of Hyg. $x$ 
March 25. The epizootic commenced among the uninoculated rats on March 29, the following series of deaths occurring :-

\begin{tabular}{|c|c|c|c|}
\hline March & 29 & $\ldots$ & $\ldots$ \\
\hline$"$ & 31 & $\ldots$ & $\ldots$ \\
\hline April & 1 & $\ldots$ & $\ldots$ \\
\hline " & 2 & $\ldots$ & $\ldots$ \\
\hline " & 3 & $\ldots$ & $\ldots$ \\
\hline " & 6 & $\ldots$ & $\ldots$ \\
\hline
\end{tabular}

Five inoculated rats were added on April 7, all of which died of plague by April 11. Another uninoculated rat died of plague on April 16, bringing the total up to 12. A third lot of five inoculated rats was added on April 19, all of which died of plague by April 22. No more uninoculated rats developed plague. The average number of fleas during the experiment was thirty per rat. No plague rats were eaten.

Godown No. 12. Fifteen uninoculated rats were put in on March 22, along with five inoculated rats. Three of the inoculated rats died on March 24. Five more added on April 4 and a third lot of five on April 19: all died of plague. The epizootic entirely failed to light up in this godown, a single unınoculated rat dying of plague on April 10. The average number of fleas per rat was 21 . No plague rats were eaten. The fourteen survivors and a similar number of rats from the control godowns were inoculated with 1 c.c. each of a 1 in 5000 emulsion of the spleen of a rat dead of acute plague; none of the former died of plague while of the controls 12 succumbed.

Experiment XII. March 22 nd to May 2nd.

\begin{tabular}{|c|c|c|c|c|c|c|}
\hline \multirow{3}{*}{$\begin{array}{c}\text { Godown } \\
\text { No. } 7\end{array}$} & \multirow{2}{*}{\multicolumn{2}{|c|}{$\begin{array}{l}\text { Inoculated rats } \\
\text { Put in Dead of plague }\end{array}$}} & \multicolumn{2}{|c|}{ Uninoculated rats } & \multirow{2}{*}{$\begin{array}{l}\text { Plague rats } \\
\text { eaten }\end{array}$} & \multirow[b]{2}{*}{ Flea count } \\
\hline & & & Put in & Dead of plague & & \\
\hline & 15 & 15 & 15 & $\mathbf{0}$ & 0 & $\begin{array}{l}\text { One flea found on } \\
\text { April } 25 \text {. }\end{array}$ \\
\hline No. 8 & 15 & 14 & 15 & $\mathbf{0}$ & 0 & Nil. \\
\hline No. 9 & 15 & 14 & 15 & $\mathbf{0}$ & 0 & $\begin{array}{l}\text { Four fleas found on } \\
\text { April } 25 \text {. }\end{array}$ \\
\hline No. 10 & 5 & 5 & 15 & 15 & 0 & Average 11 per rat. \\
\hline No. 11 & 15 & 15 & 15 & 12 & 0 & Average 30 per rat. \\
\hline No. 12 & 15 & 13 & 15 & $\mathbf{1}$ & 0 & Average 21 per rat. \\
\hline
\end{tabular}




\section{Summary and Conclusions.}

Taking the whole series of twelve experiments, involving twenty-two observations in godowns infested with fleas and the same number done in parallel in control godowns, we obtain the following crude figures :-

$\begin{array}{lll} & \text { Control godowns } & \text { Flea godowns } \\ \text { Inoculated rats put in } & 253 & 185 \\ " \# \text { died of plague } & 217=85 \cdot 7 \% & 158=85 \cdot 4 \% \\ \text { Uninoculated rats put in } & 382 & 381 \\ " \# \text { died of plague } & 17=4 \cdot 4 \% & 163=\mathbf{4 2} \cdot \mathbf{8} \% \\ \text { Plague rats eaten } & 23 & 20 \\ \text { Fleas present } & \text { Few or none } & \text { Some or many. }\end{array}$

In many cases however-fourteen out of twenty-two-the control godowns did not remain absolutely free from fleas throughout the experiment. Excluding these, and taking only the eight experiments in which no flea was ever found in the control godowns, together with the corresponding parallel experiments in flea-infested godowns, the figures come out as follows:-

$\begin{array}{lcc} & \text { Control godowns } & \text { Flea godowns } \\ \text { Inoculated rats put in } & 84 & 70 \\ \text { " died of plague } & 73=86.9 \% & 63=90 \cdot 0 \% \\ \text { Uninoculated rats put in } & 125 & 125 \\ \text { " died of plague } & 0 & \mathbf{6 7}=\mathbf{4 5 . 6} \% \\ \text { Plague rats eaten } & 3 & \mathbf{1} \\ \text { Fleas present } & \text { None } & \text { ca. } 24 \text { per rat. }\end{array}$

In seven other experiments, very few fleas were present, one or two only being found in several cases after the test examinations had shown no fleas for a month or more. These experiments with their corresponding flea godowns give these figures :-

$\begin{array}{lcc} & \text { Control godowns } & \text { Flea godowns } \\ \text { Inoculated rats put in } & 89 & 70 \\ \text { " died of plague } & 78=87.6 \% & 64=91.4 \% \\ \text { Uninoculated rats put in } & 105 & 105 \\ \text { " died of plague } & \mathbf{1}=1 \% & \mathbf{3 8}=\mathbf{3 6 . 2} \% \\ \text { Plague rats eaten } & 1 & 5 \\ \text { Fleas present } & \text { ca. } 1.5 \text { per godown } & \text { ca. 9 per rat. }\end{array}$

From these results it is clear that epidemic infection spreads readily enough from rats inoculated with plague to healthy rats living with them under the conditions of these experiments if a good number of rat fleas are 
present, and that under precisely the same conditions ${ }^{1}$, except only that fleas are absent or present in very small numbers, no epidemic occurs. In no case did an epidemic arise in the absence of fleas, though in three cases there was no material spread of infection though fleas were plentiful. Since the number of rats dead of plague which were eaten by their companions was practically identical in the two sets of experiments, it follows that there is no reason for thinking that alimentary infection played any part in the production of these epidemics.

It would involve unnecessary repetition to note in detail the various features of interest in the different experiments. Special attention may however be drawn to experiments I and III. In the former though 9 out of 13 rats dead of plague in the control godown were eaten by their companions, only one of 25 uninoculated rats died of plague, while in the corresponding flea godown 1 of 8 was eaten and 13 of 30 caught plague. In the latter, the control godown remained free from fleas for forty days and no uninoculated rat died of plague; fleas then gained access somehow or other and an epizootic of six deaths in nine days immediately occurred.

The reasons for the variation in the flea prevalence and the intensity of the epidemics at different times will be discussed in a later paper when further experiments now in hand are completed.

The immunity to plague of the rats left alive was tested at the end of a number of the experiments. The controls used were fresh Bombay rats, many of which are more or less immune. In each case the godown rats and the controls all had the same dose of an emulsion of plague-rat spleen, and in any one experiment the results are comparable. The different experiments cannot however be compared with one another.

A. From flea-infested godowns :-

$\begin{array}{cc}\text { Tested } & \text { Dodown rats } \\ 14 & 0 \\ 9 & 0 \\ 4 & 0 \\ 9 & 0 \\ 24 & 0 \\ 14 & 0\end{array}$

\begin{tabular}{cr}
\multicolumn{2}{c}{ Control rats } \\
Tested & Died \\
30 & 18 \\
30 & 18 \\
2 & 1 \\
23 & 9 \\
$38^{2}$ & 10 \\
$14^{2}$ & 12
\end{tabular}

1 Except for fleas, the conditions varied only in the number of inoculated rats dying of plague, i.e. in the quantity of potential infection presented to the uninoculated rats. But it will be seen that in all cases this was less in the flea than in the control godowns, so that, if anything, the uninoculated rats in the flea godowns had less chance of being infected than the controls.

2 In these cases (Experiments XI and XII) the control rats were those surviving in the control godowns in which there had been no spread of infection. 
B. From control godowns in which there had been some spread of infection:-

$\begin{array}{cc}\text { Tested } & \text { Dodown rats } \\ 12 & 4 \\ 10 & 8 \\ 9 & 3\end{array}$

\begin{tabular}{|c|c|}
\hline \multicolumn{2}{|c|}{ Control rats } \\
\hline Tested & Died \\
\hline 20 & 19 \\
\hline 20 & 19 \\
\hline 23 & 9 \\
\hline
\end{tabular}

C. From control godowns which had remained flea-free :-

$\begin{array}{cc}\text { Tested } & \text { Godown rats } \\ 16 & 15 \\ 16 & 7\end{array}$

\begin{tabular}{|c|c|}
\hline \multicolumn{2}{|c|}{ Control rats } \\
\hline Tested & Die \\
\hline 20 & 19 \\
\hline 23 & 9 \\
\hline
\end{tabular}

It is not worth while attempting a numerical expression of the results, but it is clear that the rats which survived these experimental epidemics were very resistant to plague. The same thing is shown by the failure (Experiments XI and XII) to restart an epidemic among the survivors by introducing fresh inoculated rats. In all 29 out of 75 rats died after the first dose of inoculated rats; only three of the 46 survivors died after a second dose, and none out of 17 which were tested by a third dose. But it is questionable whether the resistance of the survivors was greater than that of the same animals when the experiment started. Thus the 74 rats from flea-infested godowns, none of which succumbed to subcutaneous inoculation of plague, were the ultimate survivors of 143 wild Bombay rats, 60 of which had died from flea infection in the godowns. In other words, 74 of $143(52 \%)$ were resistant, or, excluding the rats which died from causes other than plague in the godowns, 74 of $135(55 \%)$. With doses of the order of those used in making these immunity experiments, it is not improbable that $50 \%$ of fresh Bombay rats would survive (see also vol. vi. pp. 505, 506). As a matter of fact about $45 \%$ of the fresh rats used as controls did not die of plague, so that there is no evidence that there was any acquisition of immunity during the course of the experiments from subminimal infections. 


\section{APPENDIX.}

The following table shows the distribution of the primary bubo in rats dying of plague contracted in the godowns in Experiments VIIIXII.

\begin{tabular}{lllllr} 
Cervical & $\ldots$ & $\ldots$ & $\ldots$ & $\ldots$ & 84 \\
Axillary & $\ldots$ & $\ldots$ & $\ldots$ & $\ldots$ & 4 \\
Inguinal & $\ldots$ & $\ldots$ & $\ldots$ & $\ldots$ & 1 \\
Pelvic & $\ldots$ & $\ldots$ & $\ldots$ & $\ldots$ & 1 \\
No bubo & $\ldots$ & $\ldots$ & $\ldots$ & $\ldots$ & 3 \\
Too much eaten for diagnosis & $\ldots$ & $\ldots$ & 4 \\
\hline
\end{tabular}

It will be remembered that the same preponderance of cervical buboes was found in wild rats naturally infected with plague, in rats infected by transference of fleas and in guinea-pigs infected in the previous godown experiments (see vol. vI. p. 465, vol. vII. pp. $382 \mathrm{ff}$ ). 